\title{
Roles of Graphene Additives in Optimizing the Microstructure and Properties of $\mathrm{Ni}-\mathrm{Cr}-\mathrm{Graphene}$ Coatings
}

\author{
Liang Meng ${ }^{1,2, *}$, Qinyou $\mathrm{Hu}^{1}$, Chaojian Shi ${ }^{1, *}$ and Changhai Huang ${ }^{1(D)}$ \\ 1 Merchant Marine College, Shanghai Maritime University, Shanghai 201306, China; \\ qyhu@shmtu.edu.cn (Q.H.); chhuang@shmtu.edu.cn (C.H.) \\ 2 Anhui Register of Shipping Bureau of Huai River, Bengbu 233000, China \\ * Correspondence: 201140110003@stu.shmtu.edu.cn (L.M.); cjshi@shmtu.edu.cn (C.S.)
}

Received: 28 December 2019; Accepted: 16 January 2020; Published: 24 January 2020

\begin{abstract}
The electrodeposition technique was used to fabricate graphene and $\mathrm{Cr}$ particle-reinforced $\mathrm{Ni}-\mathrm{Cr}$-graphene coatings. The Rietveld refinement was utilized to analyze the microstructure of $\mathrm{Ni}$ deposits in the coatings. The properties including micro-hardness and corrosion behaviors of the coatings were also tested. Results showed that the addition of graphene particles contributed to the dendrite like structure on the surface of the $\mathrm{Ni}-\mathrm{Cr}$-graphene coating. The crystallite size and [200] texture of the $\mathrm{Ni}$ deposits in the $\mathrm{Ni}-\mathrm{Cr}$-graphene coatings were significantly decreased by the graphene particles. The crystallite size of $149.8 \mathrm{~nm}$ in the $\mathrm{Ni}-25-\mathrm{Cr}-0$-graphene coating was reduced to $35 \mathrm{~nm}$ in the Ni-25-Cr-8-graphene coating due to the addition of $8 \mathrm{~g} / \mathrm{L}$ graphene to the electrolyte. The microstructure evolution of the $\mathrm{Ni}-\mathrm{Cr}$-graphene coatings brought about an enhancement in micro-hardness and corrosion resistance of the coatings. The micro-hardness of the coatings was improved from $260.1 \mathrm{HV}_{0.2}$ of the pure $\mathrm{Ni}$ coating to $285.9 \mathrm{HV}_{0.2}$ of the $\mathrm{Ni}-25-\mathrm{Cr}-0$-graphene coating and continually to $461.8 \mathrm{HV}_{0.2}$ of the $\mathrm{Ni}-25-\mathrm{Cr}-8$-graphene coating. In corrosion solution (3.5 wt.\% $\mathrm{NaCl})$, the corrosion current $\left(6.22 \mu \mathrm{A} / \mathrm{cm}^{2}\right)$ of the Ni-25-Cr-0-graphene coating could be decreased by about an order of magnitude through the addition of graphene particles, which was $0.33 \mu \mathrm{A} / \mathrm{cm}^{2}$ for the Ni-25-Cr-8-graphene coating.
\end{abstract}

Keywords: Ni-Cr-graphene coating; electrodeposition; microstructure; micro-hardness; corrosion resistance

\section{Introduction}

As one of the most important surface engineering coatings, Ni-based composite coatings possess superior resistance to oxidation, wear, and corrosion, and they are extensively used to cope with severe environments [1,2]. Particle reinforcements including nonmetallic and metallic particles (such as $\mathrm{Al}_{2} \mathrm{O}_{3}, \mathrm{CeO}_{2}, \mathrm{Al}, \mathrm{Cr}$, and Ti particles) can be co-deposited onto $\mathrm{Ni}$ deposits to establish Ni-based composite coatings by electrodeposition [1,3-9]. The co-deposition behaviors of the particle additives contribute to an optimized microstructure, e.g., decreased crystallite size and diminished preferential growth orientation of nickel deposits, which consequently enhance the properties of the Ni composite coatings [5,9].

Among the particle additives, $\mathrm{Cr}$ particles are extensively adopted to fabricate $\mathrm{Ni}-\mathrm{Cr}$ composite coatings with enhanced micro-hardness, high temperature oxidation, and corrosion and wear resistance [6-8]. Peng et al. [1] electrodeposited Ni-Cr coatings and suggested that the $\mathrm{Ni}-\mathrm{Cr}$ coatings possessed decreased crystallite size with respect to Ni deposits, which was induced by the co-deposition of $\mathrm{Cr}$ particles. Meanwhile, the incorporation of $\mathrm{Cr}$ particles reduced the possibility of localized corrosion in $\mathrm{NaCl}$ solution and consequently enhanced the corrosion resistance of the coatings. 
Zhao et al. [6] suggested that $\mathrm{Cr}$ particles gave birth to the crystallite refinement of $\mathrm{Ni}$ deposits and consequently enhanced the micro-hardness and wear resistance of the $\mathrm{Ni}-\mathrm{Cr}$ coatings. Additionally, some kinds of particles such as $\mathrm{CeO}_{2}, \mathrm{Al}$, and $\mathrm{SiC}$ worked as modification particles to further optimize the microstructure and properties of the $\mathrm{Ni}-\mathrm{Cr}$ coatings $[7,10,11]$. Dong et al. [7] suggested that $\mathrm{CeO}_{2}$ modification particles lowered the oxidation kinetics of $\mathrm{Ni}-\mathrm{Cr}$ composite coatings by further modifying the microstructure of $\mathrm{Ni}-\mathrm{Cr}$ coatings and promoting the formation of oxide scale. Therefore, these modification particles can further decrease the crystallite size of the Ni deposits, thereby improving the properties of the $\mathrm{Ni}-\mathrm{Cr}$ coating with the intrinsic roles of the modification particles.

As an emerging two-dimensional structure of free-standing carbon atoms, graphene attracts lots of scientific attention due to its desirable electrical, thermal, mechanical, and physical properties [12]. Graphene is extensively used as a particle additive to fabricate $\mathrm{Ni}$-graphene composite coatings, which exhibit superior corrosion resistance, wear resistance, and micro-hardness [13-16]. The electrodeposition behaviors of graphene can enable the graphene particles to be incorporated into the $\mathrm{Ni}-\mathrm{Cr}$ composite coating and consequently establish an $\mathrm{Ni}-\mathrm{Cr}$-graphene composite coating. Therefore, an idea of the preparation of graphene-modified $\mathrm{Ni}-\mathrm{Cr}$-graphene composite coatings was established, in which the graphene works as the modification particle. These coatings can have potentially desirable properties including superior corrosion resistance and micro-hardness. Investigations into the modification effects of graphene additives on the microstructure and properties of the Ni-Cr-graphene coatings need to be comprehensively carried out, which can greatly contribute to the broad applications of graphene-modified $\mathrm{Ni}-\mathrm{Cr}$-graphene coatings.

In the present work, different concentrations of graphene particles accompanied by a given concentration of $\mathrm{Cr}$ particles were co-deposited to establish the $\mathrm{Ni}-\mathrm{Cr}$-graphene coatings. The roles of graphene modification particles in optimizing the microstructure, including crystallite size and crystallographic orientation, and properties of the $\mathrm{Ni}-\mathrm{Cr}-$ graphene coatings were comprehensively investigated. The micro-hardness and corrosion behaviors of the $\mathrm{Ni}-\mathrm{Cr}$-graphene coatings were also comprehensively evaluated.

\section{Materials and Methods}

\subsection{Preparation of $\mathrm{Ni}-\mathrm{Cr}-\mathrm{Graphene}$ Coatings}

The electrodeposition technique was adopted to fabricate the Ni-Cr-graphene composite coatings. The electrodeposition electrolyte was a Watts bath containing a certain concentration of $25 \mathrm{~g} / \mathrm{L} \mathrm{Cr}$ particles and different concentrations of graphene particles $(0,1,2,4$, and $8 \mathrm{~g} / \mathrm{L})$. The expression of $\mathrm{Ni}-x-\mathrm{Cr}-y$-graphene was used to describe the coating electrodeposited at $x \mathrm{~g} / \mathrm{L}$ concentration of $\mathrm{Cr}$ and $y \mathrm{~g} / \mathrm{L}$ concentration of graphene particles. The sizes of the as-received $\mathrm{Cr}$ and graphene particles were about 1 and $10 \mu \mathrm{m}$ (see Figure 1), respectively. The agglomeration of $\mathrm{Cr}$ particles can be seen in Figure 1a. The substrate materials, which worked as the cathode in electrodeposition, were nickel aluminum bronze alloys (NAB) with a surface area of $2 \mathrm{~cm}^{2}$. Meanwhile, the anode materials were nickel plates with a surface area of $5 \mathrm{~cm}^{2}$. These two electrodes were fixed in parallel, with a distance of $30 \mathrm{~mm}$. In electrodeposition, magnetic agitation at $350 \mathrm{rpm}$ was maintained to suspend the particles. A direct current of $5 \mathrm{~A} / \mathrm{dm}^{2}$ was adopted to fabricate the coatings until the thicknesses reached ca. $60 \mu \mathrm{m}$. The electrodeposition parameters are shown in Table 1. 


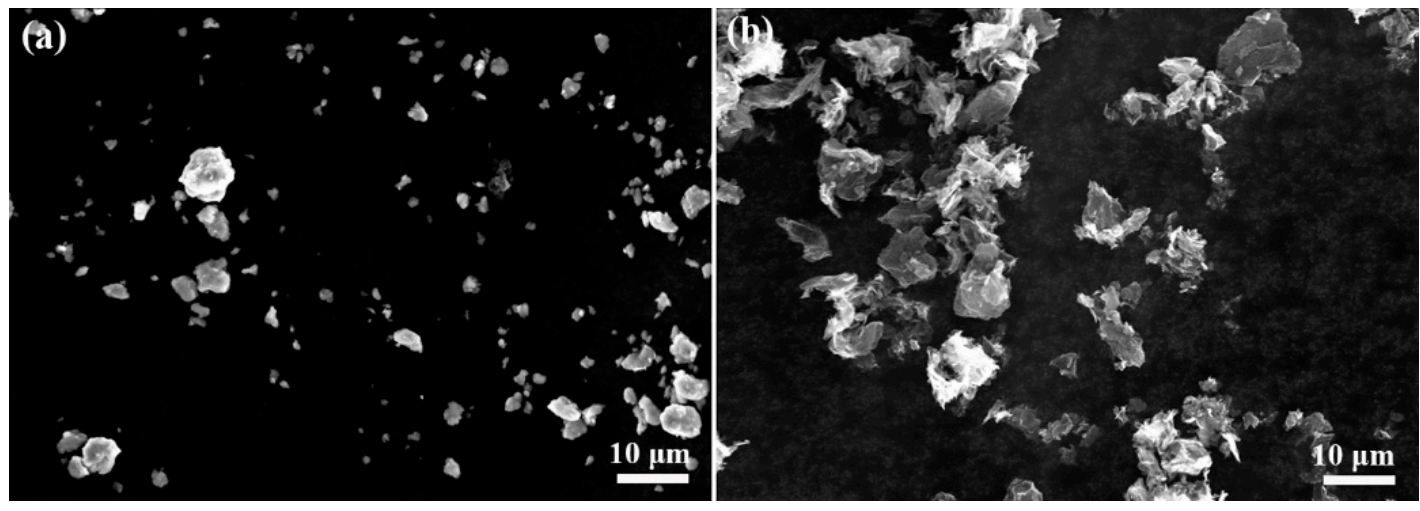

Figure 1. SEM morphologies of the $\mathrm{Cr}(\mathbf{a})$ and graphene particles (b).

Table 1. Bath composition and electrodeposition conditions.

\begin{tabular}{ccc}
\hline Bath Composition & Concentration $(\mathrm{g} / \mathrm{L})$ & Electrodeposition Conditions \\
\hline $\mathrm{NiSO}_{4}$ & 240 & Current density: $5 \mathrm{~A} / \mathrm{dm}^{2}$ \\
$\mathrm{NiCl}_{2}$ & 40 & pH: 3.5 \\
$\mathrm{H}_{3} \mathrm{BO}_{3}$ & 30 & Temperature: $45^{\circ} \mathrm{C}$ \\
$\mathrm{C}_{12} \mathrm{H}_{25} \mathrm{SO}_{4} \mathrm{Na}$ & 0.2 & Stirring rate: $350 \mathrm{rpm}$ \\
$\mathrm{Cr}$ particles & 25 & - \\
Graphene & $0-8$ & - \\
\hline
\end{tabular}

Prior to electrodeposition, the NAB substrates were ground and then ultrasonically degreased in $1 \mathrm{~mol} / \mathrm{L} \mathrm{NaOH}$ solution for $10 \mathrm{~min}$, which was followed by ultrasonic cleaning with pure water. Then, $10 \% \mathrm{HCl}$ acid solution was used to activate the NAB substrates, which was followed by rinsing in pure water. To uniformly disperse particles, the electrodeposition electrolytes were magnetically stirred for $3 \mathrm{~h}$ and ultrasonically treated for $0.5 \mathrm{~h}$. Once each electrodeposition process ended, the $\mathrm{Ni}-\mathrm{Cr}-\mathrm{graphene}$ coating was ultrasonically cleaned in pure water.

\subsection{Characterization of $\mathrm{Ni}-\mathrm{Cr}-\mathrm{Graphene}$ Coatings}

The morphologies of the Ni-Cr-graphene coatings were characterized by scanning electron microscopy (SEM, Hitachi TM3030, Tokyo, Japan). Raman spectroscopy (LabRAMHR, Horiba Jobin Yvon, France), energy-dispersive spectroscopy (EDS, Oxford Swift 3000, Oxford, UK), and X-ray diffraction (XRD, Rigaku Ultima IV, Tokyo, Japan) analysis were employed to analyze the chemical composition and microstructure of the coatings. Rietveld refinements were utilized to analyze the XRD results of the coatings with the MAUD software (version 2.33) [17]. The crystallite information of Ni deposits, including crystallite size and crystallographic orientation, was obtained. In Rietveld refinements, the pseudo-Voigt $(\mathrm{pV})$ function [18] was adopted to fit $\mathrm{K}_{\mathrm{a} 1}$ and $\mathrm{K}_{\mathrm{a} 2}$ [19], which was expressed as follows:

$$
\begin{gathered}
\mathrm{pV}(2 \theta)=\sum_{a_{1} a_{2}} I_{\mathrm{nt}}\left[(1-\delta)\left(1+S^{2}\right)^{-1}+\delta \exp \left(-\ln 2 \times S^{2}\right)\right] \\
S=\frac{2 \theta-2 \theta_{0}}{\beta}
\end{gathered}
$$

where $I_{\mathrm{nt}}, \theta_{0}, \beta$, and $\delta$ are the scale parameter of the $\mathrm{pV}$ function, the Bragg angle of Ka $\mathrm{K}_{1}$ radiation, the full width at half maximum, and the Gaussian component, respectively. The Popa LB model and Popa rules were used to calculate the line broadening and anisotropic crystallites [20]. The deformation and twin faults could induce shifts, broadening, and asymmetry in the XRD profile, which was refined by the Warren model [21]. The pole figures of (111), (200), and (220) planes could be obtained from 
the harmonic texture model, which could be verified by the relative texture coefficients (RTC) of (hkl) peaks as follows [22]:

$$
\operatorname{RTC}_{(\mathrm{hkl})}=\frac{I_{(\mathrm{hkl})} / I_{0(\mathrm{hkl})}}{\sum I_{(\mathrm{hkl})} / I_{0(\mathrm{hkl})}} \times 100 \%
$$

where $I_{(\mathrm{hkl})}$ and $I_{0(\mathrm{hkl})}$ are the (hkl) peak intensities of the coatings and the standard Ni powders, respectively.

The Vickers micro-hardness of the Ni-Cr-graphene coatings was measured using a micro-hardness tester (HXD-1000TMC/LCD, Shanghai TaiMing optical instruments, Shanghai, China) with $200 \mathrm{~g}$ of load and $15 \mathrm{~s}$ of dwelling time. In a $4 \mathrm{~mm} \times 4 \mathrm{~mm}$ square area of the surface, the micro-hardness of 25 points was evenly measured at an interval of $1 \mathrm{~mm}$. The final micro-hardness of the coating was obtained from the average values of micro-hardness of 25 points.

In $3.5 \mathrm{wt} . \% \mathrm{NaCl}$ solution, the electrochemical corrosion experiments were carried out using an electrochemical workstation (Autolab PGSTAT302N, Metrohm, the Netherlands) at $25{ }^{\circ} \mathrm{C}$. Electrochemical impedance spectra (EIS) and potentiodynamic polarization experiments were conducted. The Ni-Cr-graphene coatings with surface area of $1 \mathrm{~cm}^{2}$, platinum sheet, and saturated $\mathrm{Ag} / \mathrm{AgCl}$ electrode (+198 mV) built a three-electrode system, which acted as the working, counter, and reference electrodes, respectively. In potentiodynamic polarization experiments, the anodic/cathodic Tafel slopes $\left(b_{\mathrm{a}}\right.$ and $\left.b_{\mathrm{c}}\right)$, corrosion potential $\left(E_{\mathrm{corr}}\right)$, and corrosion current $\left(I_{\mathrm{corr}}\right)$ were obtained with a scanning speed of $1 \mathrm{mV} / \mathrm{s}$. At the open circuit potential, EIS experiments, including Nyquist plots and Bode plots, were conducted. The scanning frequency was from 0.01 to $100,000 \mathrm{~Hz}$, and the potential amplitude was $10 \mathrm{mV}$. Before corrosion measurements, the coatings were immersed in $3.5 \mathrm{wt} . \% \mathrm{NaCl}$ solution for $1 \mathrm{~h}$.

\section{Results}

\subsection{Morphology and Composition of the Ni-Cr-Graphene Coatings}

The different amounts of graphene particles were incorporated into the Ni-Cr-graphene coatings. Figure 2 exhibits the surface morphologies of the coatings. It can be observed that the pure Ni coating possessed a typical pyramidal surface structure [5,9], while a dendrite-like structure appeared on the surface of the Ni-Cr coating (see Figure $2 b$ ). This property increasingly appeared as the graphene concentration increased. When the graphene concentration reached $8 \mathrm{~g} / \mathrm{L}$, the dendrite-like structure became compact and its porosity was reduced in the surface layer of the Ni-25-Cr-8-graphene coating. 


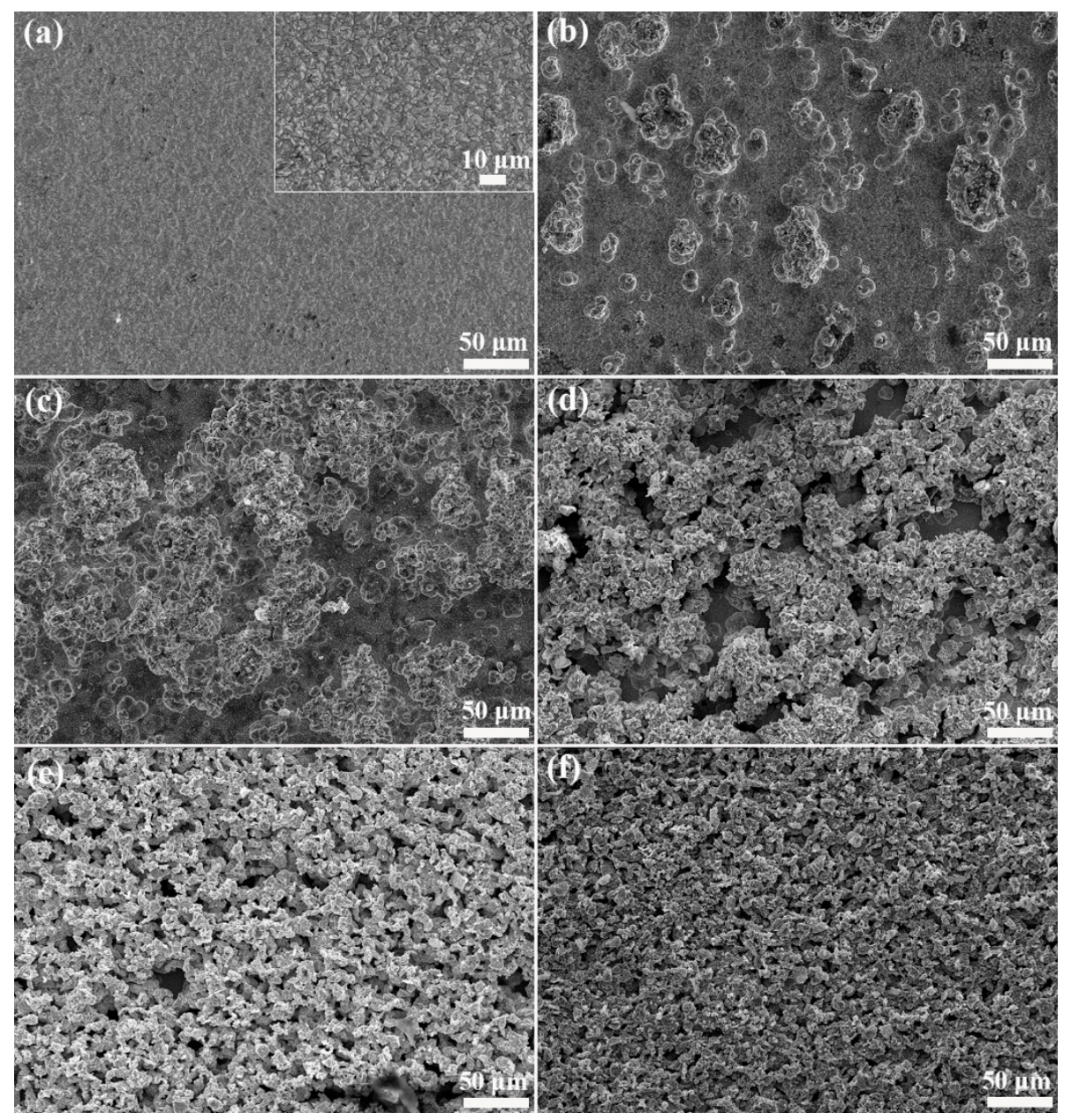

Figure 2. SEM morphologies of the Ni-Cr-graphene coatings electrodeposited with $0 \mathrm{~g} / \mathrm{L} \mathrm{Cr}$ particles (a) and $25 \mathrm{~g} / \mathrm{L} \mathrm{Cr}$ particles with various graphene concentrations of 0 (b), 1 (c), 2 (d), 4 (e), and 8 (f) g/L.

The contents of $\mathrm{Cr}$ particles in the Ni-Cr-graphene coatings are exhibited in Figure 3. It can be found that the $\mathrm{Cr}$ contents changed little among all the coatings, approaching ca. $7.7 \mathrm{wt} . \%$ on average. Figure 4 shows the EDS analysis results of the different coatings. With careful observation, the shapes of $\mathrm{Ni}$ and $\mathrm{Cr}$ peaks remained almost consistent among different coatings. However, the peak intensity of $C$ gradually increased as the graphene concentration increased, which demonstrated the increase in graphene content in the coatings. To verify the EDS results, the Raman analysis of graphene in the Ni-Cr-graphene coatings is exhibited in Figure 5. Two strong peaks of D and G appeared for the graphene particles, located at $1348 \mathrm{~cm}^{-1}$ and $1590 \mathrm{~cm}^{-1}$, respectively. For the $\mathrm{Ni}-\mathrm{Cr}$-graphene coatings electrodeposited at 0,1 , and $2 \mathrm{~g} / \mathrm{L}$, the $\mathrm{D}$ and $\mathrm{G}$ peaks of graphene were not obvious, while they were strong in the coatings electrodeposited at graphene concentrations of 4 and $8 \mathrm{~g} / \mathrm{L}$, which demonstrates the increase in graphene content in the $\mathrm{Ni}$-Cr-graphene coatings. 


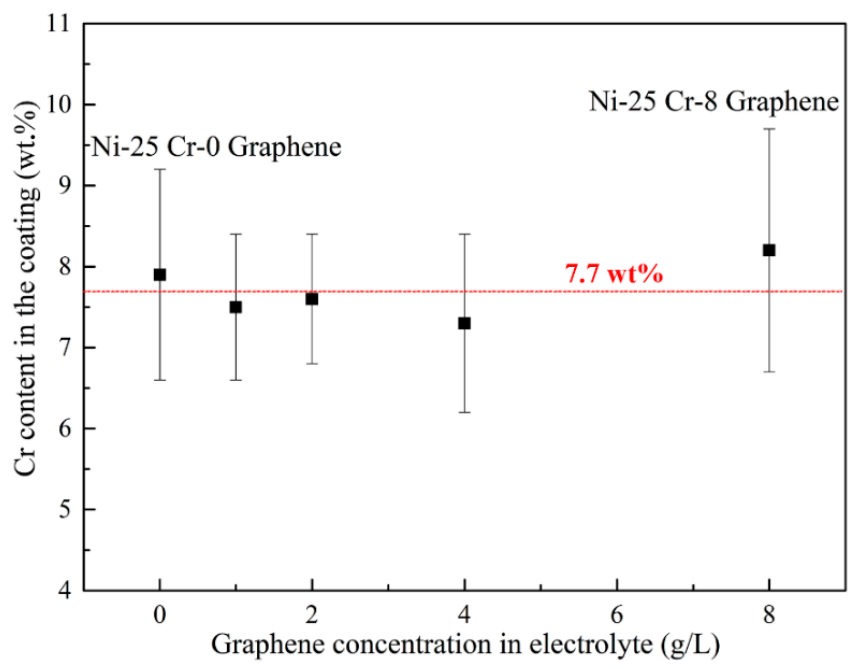

Figure 3. Content of $\mathrm{Cr}$ particles in the $\mathrm{Ni}-\mathrm{Cr}-$ graphene coatings.
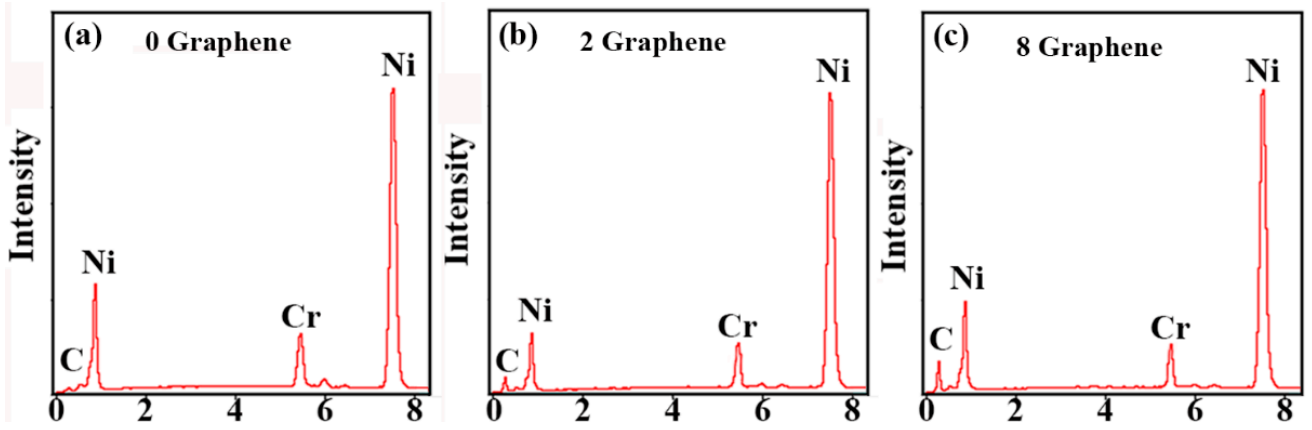

Figure 4. Energy-dispersive spectroscopy (EDS) analysis of the $\mathrm{Ni}-\mathrm{Cr}$-graphene coatings electrodeposited at different graphene concentrations: 0 (a), 2 (b), and 8 (c) g/L.

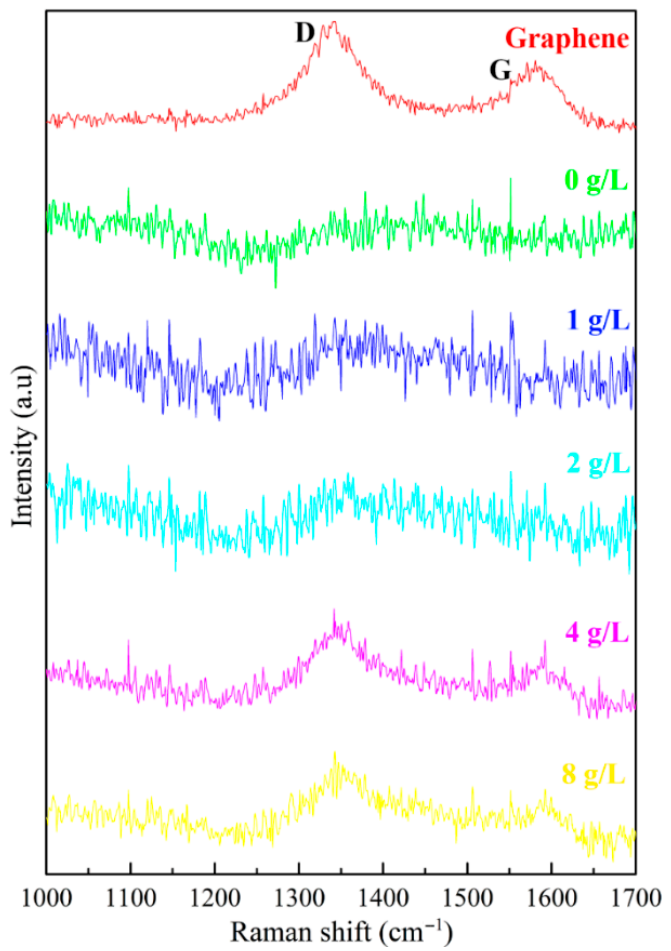

Figure 5. Raman spectra of the Ni-Cr-graphene coatings with different concentrations of graphene. 


\subsection{Microstructure of the $\mathrm{Ni}-\mathrm{Cr}-\mathrm{Graphene}$ Coatings}

The XRD results of the Ni-Cr-graphene coatings are exhibited in Figure 6, where three peaks of (111), (200), and (220) of Ni deposits can be observed for all the coatings. However, the relative intensities of the three peaks varied greatly for the various coatings. In the XRD result of the pure $\mathrm{Ni}$ coating, the (200) peak possessed greater relative intensity. With the co-deposition of $\mathrm{Cr}$ and graphene particles, the relative intensities of (200) and (111) peaks gradually decreased and increased, respectively. When the graphene concentration reached more than $4 \mathrm{~g} / \mathrm{L}$, the (111) peak intensity predominated significantly. In the magnified image of the dotted area (Figure $6 \mathrm{~b}$ ), the $\mathrm{Cr}$ peaks of (200) and (211) can be observed, illustrating that the Cr particles were co-deposited onto Ni deposits. However, the peak of graphene was not exhibited in the XRD patterns, which was induced by the low content of graphene in the coatings.

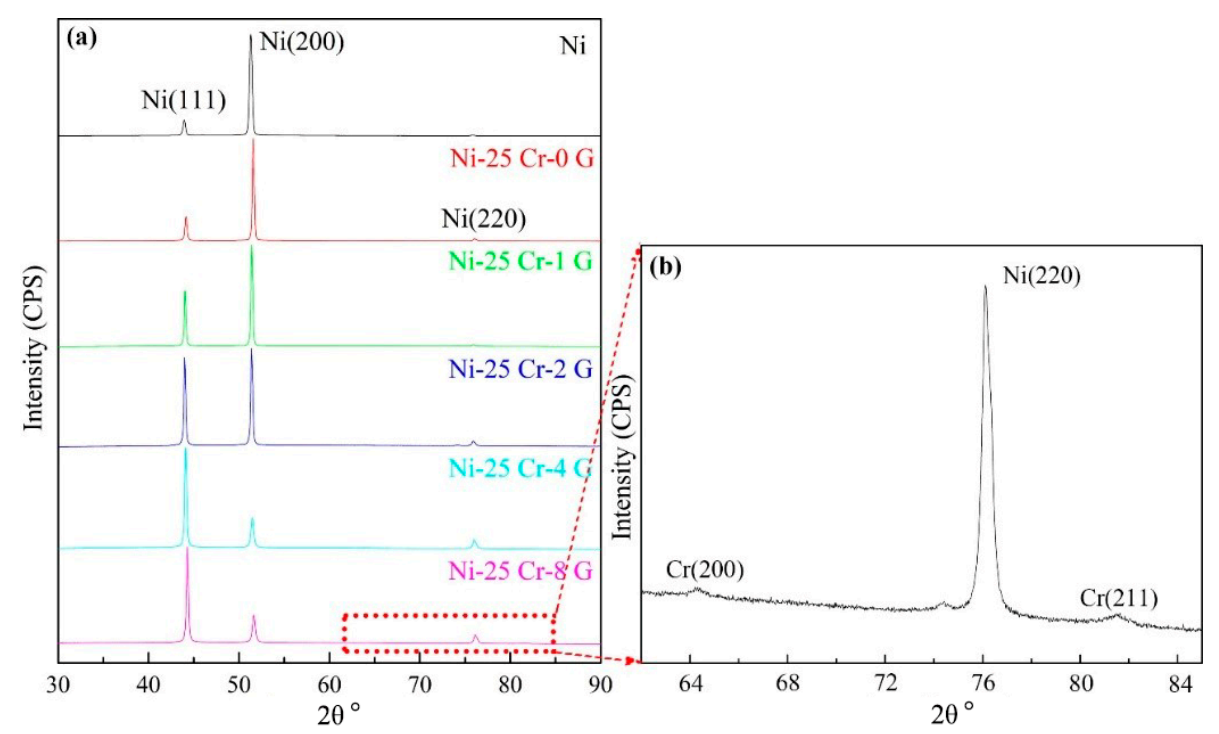

Figure 6. (a) X-ray diffraction (XRD) results of the Ni-Cr-graphene coatings with different concentrations of graphene and $(\mathbf{b})$ the magnified $X R D$ result of the dotted area in figure of (a).

The Rietveld refinement of XRD results of the Ni-Cr-graphene coatings were adopted to calculate the crystallite size, crystallite shape, and crystallographic or ientation of Ni deposits. A typical Rietveld plot of the Ni-25-Cr-8-graphene coating is exhibited in Figure 7. The value of goodness of fit (sigma, $R_{\mathrm{wp}} / R_{\exp }$ ) was 1.69 . For all the Ni-Cr-graphene coatings, the sigma values were all less than two, indicating that all refinements were feasible [23]. The crystallite sizes of Ni deposits along the [200] orientation were obtained from the Rietveld refinements (see Figure 8). The crystallite size of Ni deposits in the $\mathrm{Ni}-\mathrm{Cr}$-graphene coating decreased from 149.8 to $35.0 \mathrm{~nm}$ as the graphene concentration increased from 0 to $8 \mathrm{~g} / \mathrm{L}$, always remaining smaller than that in the pure Ni coating $(175.3 \mathrm{~nm})$. 


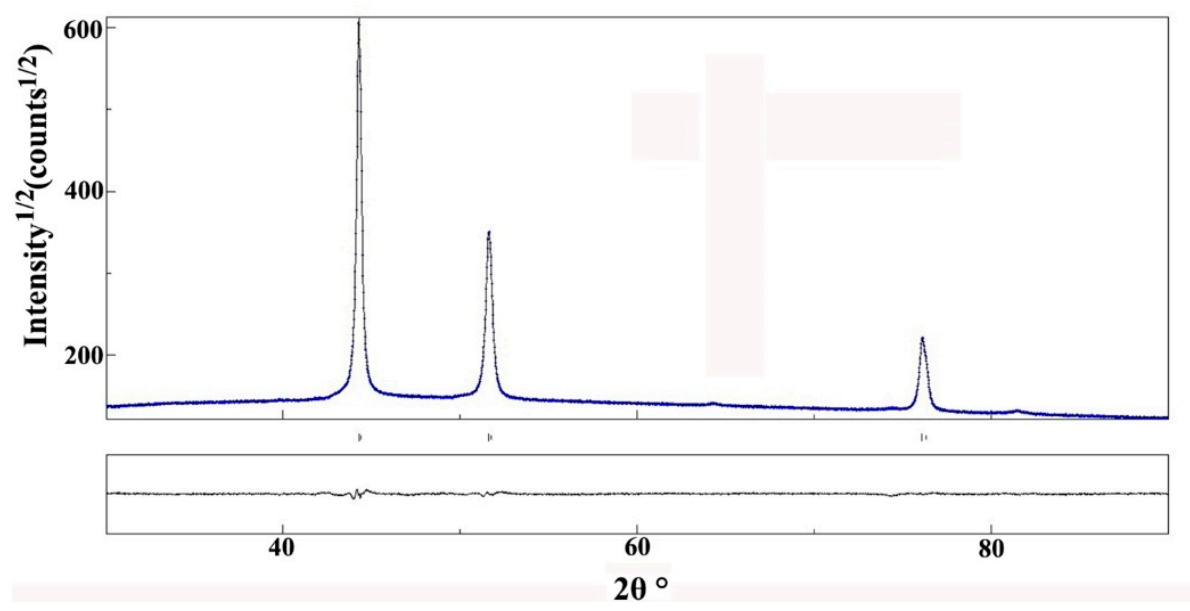

Figure 7. Rietveld plot of the Ni-Cr-graphene coatings of $8 \mathrm{~g} / \mathrm{L}$ graphene $\left(\right.$ sigma $=1.69, R_{\mathrm{W}}=1.13 \%$, $\left.R_{\exp }=0.67 \%\right)$.

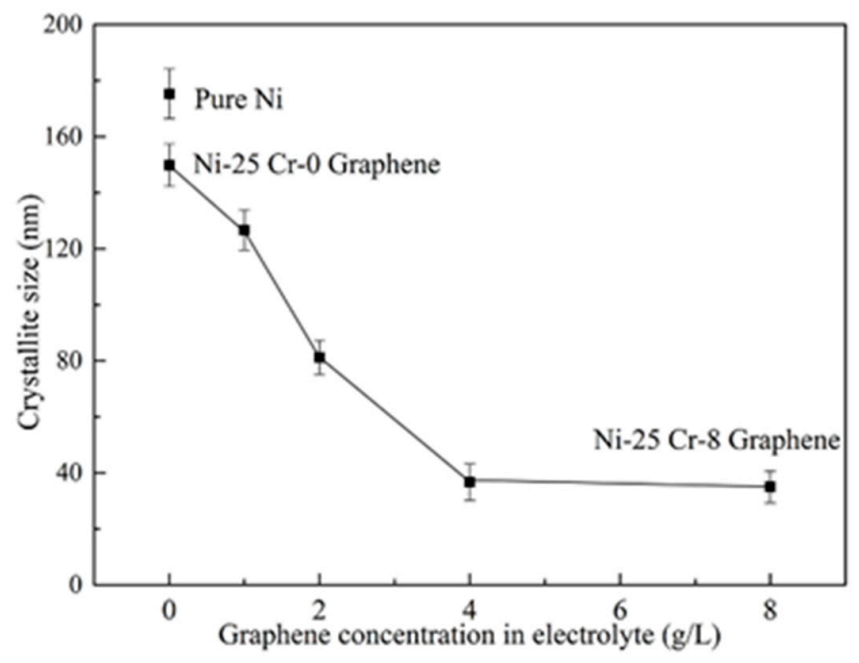

Figure 8. Crystallite size of Ni deposits in Ni-Cr-graphene coatings obtained from Rietveld refinements.

The crystallite shapes of the pure Ni and Ni-25-Cr-8-graphene coatings are exhibited in Figure 9. The white lines represent the crystallography coordinate frames (XYZ). In the crystallography coordinate system, the crystallite shapes reflect the anisotropic level of crystallite size [20,24]. It can be observed that the Ni crystallite in the pure Ni coating (Figure 9a) possessed a branched shape with larger length along the crystallography coordinate frame. The branched shape changed to a spherical shape in the $\mathrm{Ni}-25-\mathrm{Cr}$-8-graphene coating (Figure $9 \mathrm{~b}$ ) due to the co-deposition of $8 \mathrm{~g} / \mathrm{L}$ graphene particles. These results demonstrate that the crystallite sizes of $\mathrm{Ni}$ deposits in the pure Ni coating were much larger along the [100] direction. There was no obvious difference in the crystallite sizes of Ni deposits in the $\mathrm{Ni}-25-\mathrm{Cr}-8-$ graphene coating along all directions.

The crystallite shape evolution in Figure 9 reflects the changes in the crystallographic orientation of the Ni deposits in the Ni-Cr-graphene coatings, which were also pictorially built using Rietveld refinement. The detailed crystallographic orientation evolution of the $\mathrm{Ni}-\mathrm{Cr}$-graphene coatings with various concentrations of graphene is exhibited in Figure 10. It can be observed that a strong [200] fiber texture appeared in the pure Ni coating, while the [200] texture gradually diminished with increasing graphene concentration. A random crystallographic orientation appeared in the Ni-25-Cr-8-graphene coating. 

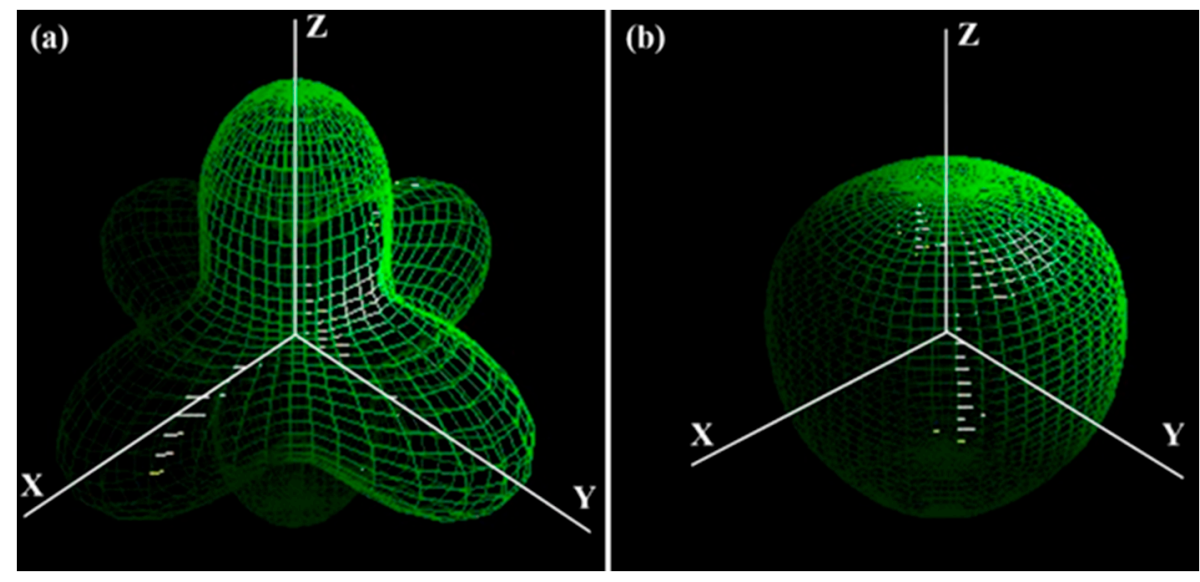

Figure 9. Crystallite shapes of Ni deposits in the pure $\mathrm{Ni}(\mathbf{a})$ and $\mathrm{Ni}-25-\mathrm{Cr}-8$-graphene (b) coatings obtained from Rietveld refinements.

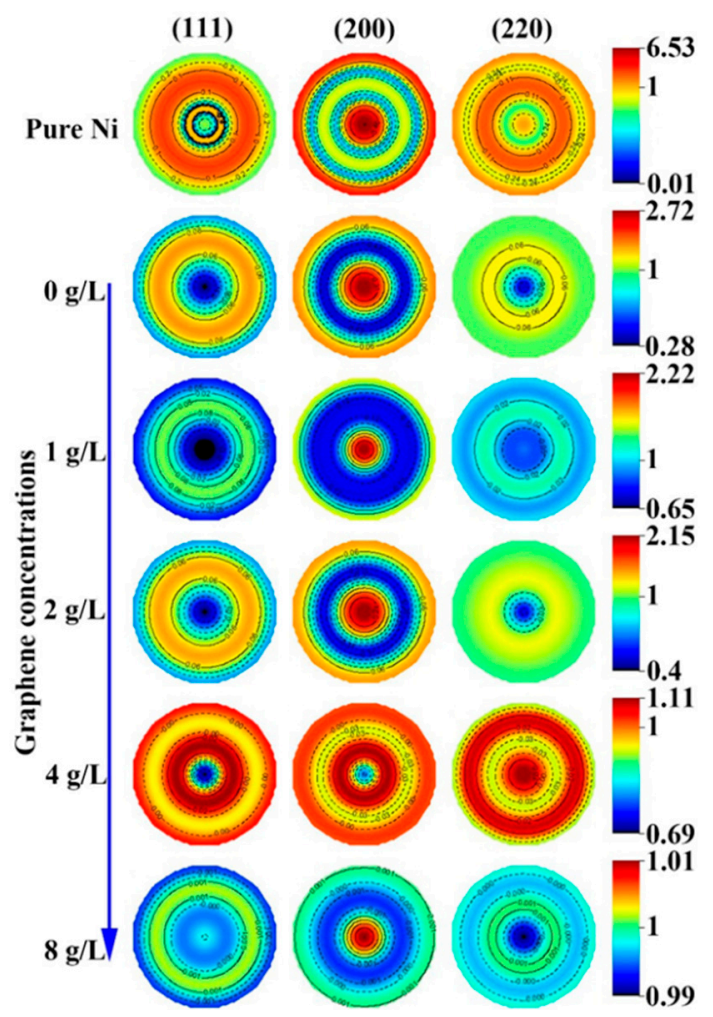

Figure 10. Pole figures of the Ni-Cr-graphene coatings obtained from Rietveld refinements.

The RTC values of different crystalline planes were also utilized to evaluate the level of crystallographic orientation [25]. In this work, the RTC values of (111), (200), and (220) planes were calculated (see Figure 11). It can be observed that the $\mathrm{RTC}_{(200)}$ decreased while $\mathrm{RTC}_{(111)}$ and $\mathrm{RTC}_{(220)}$ increased gradually with increasing graphene concentration. The values of $\mathrm{RTC}_{(200)}$ were 0.93 and 0.89 in the pure $\mathrm{Ni}$ coating and the Ni-25-Cr-0-graphene coating, respectively, illustrating that the coatings possessed a strong [200] fiber texture. The RTC results were consistent with the built pole figures of the coatings. 


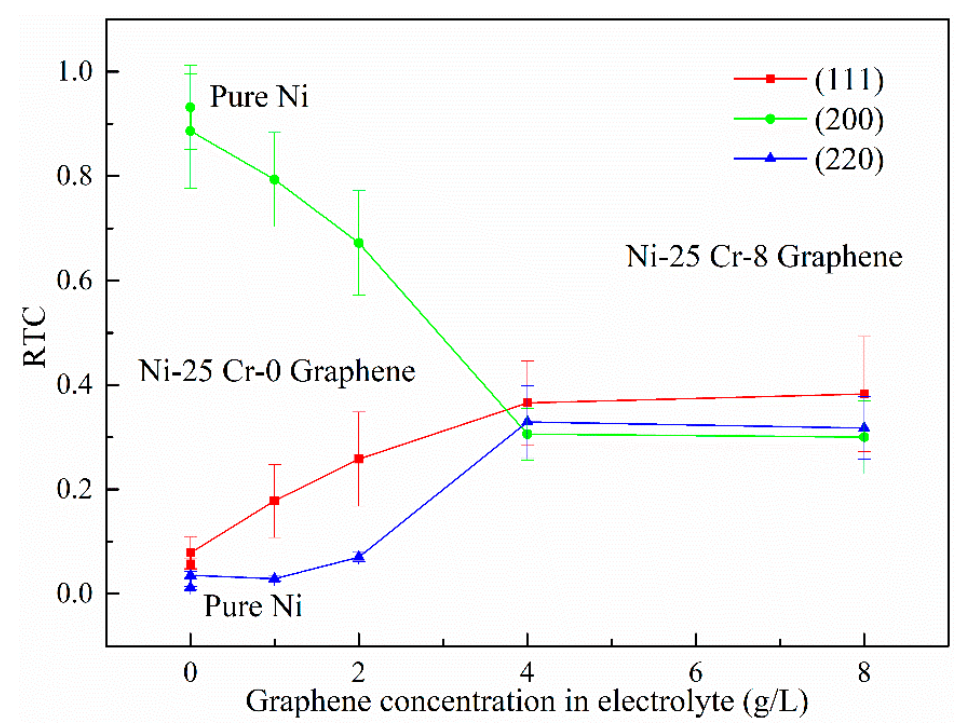

Figure 11. Relative texture coefficient $\left(\mathrm{RTC}_{(\mathrm{hkl})}\right)$ values of the $\mathrm{Ni}-\mathrm{Cr}-$ graphene coatings with respect to graphene concentration in the electrolyte.

\subsection{Micro-Hardness of the Ni-Cr-Graphene Coatings}

The surface micro-hardness variation of the $\mathrm{Ni}-\mathrm{Cr}$-graphene coatings with respect to graphene concentration in the electrolyte is exhibited in Figure 12a. The micro-hardness of the Ni-Cr-graphene coating was improved by the addition of the graphene particles, always remaining higher than that of the pure Ni coating $\left(260.1 \mathrm{HV}_{0.2}\right)$. When $8 \mathrm{~g} / \mathrm{L}$ graphene was employed as the modification particles, the micro-hardness of the Ni-25-Cr-8-graphene reached $461.8 \mathrm{HV}_{0.2}$. Furthermore, the surface micro-hardness distribution of the pure $\mathrm{Ni}$ and the $\mathrm{Ni}-25-\mathrm{Cr}-8$-graphene coatings are exhibited in Figure $12 \mathrm{~b}, \mathrm{c}$. The micro-hardness of the Ni-25-Cr-8-graphene coating was apparently larger than that of the pure Ni coating, whereas their distributions became less uniform.

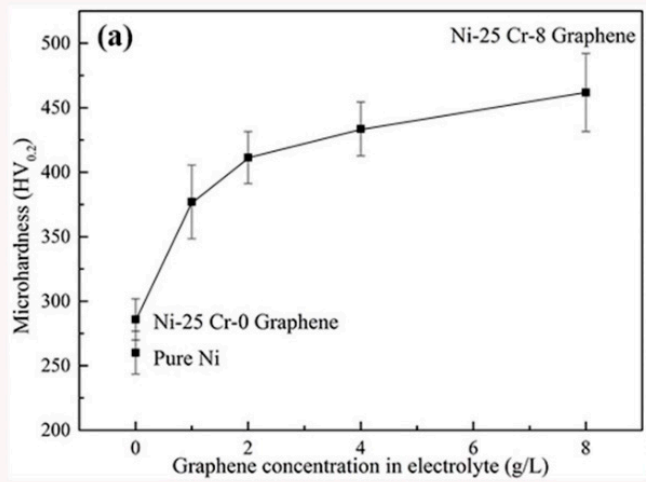

(b)

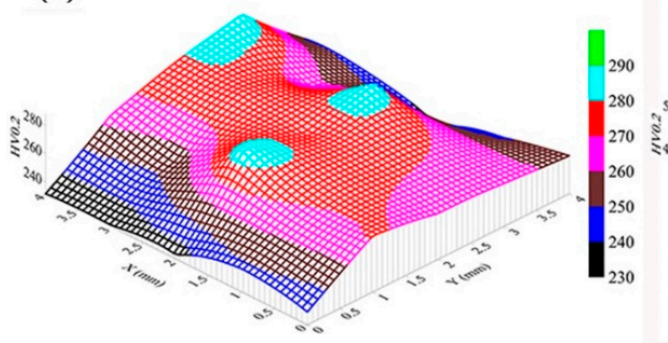

(c)

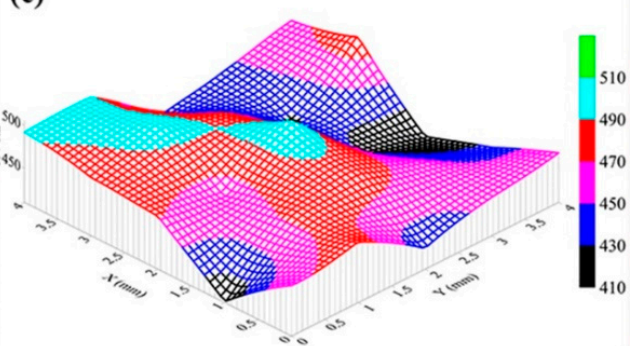

Figure 12. Micro-hardness variation of the Ni-Cr-graphene coatings (a); surface micro-hardness distribution of the pure $\mathrm{Ni}(\mathbf{b})$ and $\mathrm{Ni}-25-\mathrm{Cr}-8-$ graphene (c) coatings. 


\subsection{Corrosion Behaviors of the Ni-Cr-Graphene Coatings}

The potentiodynamic polarization curves of the Ni-Cr-graphene coatings are shown in Figure 13. Based on these curves, the extrapolation method was used to calculate the $E_{\text {corr }}$ and $I_{\text {corr }}$ of the coatings (see Table 2). The $E_{\text {corr }}$ of the Ni-Cr-graphene coatings gradually improved from -0.36 to $-0.20 \mathrm{mV}$ with increasing graphene concentration from 0 to $8 \mathrm{~g} / \mathrm{L}$. The $E_{\text {corr }}$ of the $\mathrm{Ni}-\mathrm{Cr}$-graphene coatings were obviously more positive than that of the pure Ni coating $(-0.41 \mathrm{mV})$. Meanwhile, the $I_{\text {corr }}$ decreased from $7.01 \mu \mathrm{A} / \mathrm{cm}^{2}$ for the pure Ni coating to $0.33 \mu \mathrm{A} / \mathrm{cm}^{2}$ for the Ni-25-Cr-8-graphene coatings with increasing graphene concentration. The $\mathrm{Ni}-25-\mathrm{Cr}-8$-graphene coating possessed the best corrosion resistance with the highest $E_{\text {corr }}$ and the lowest $I_{\text {corr }}$.

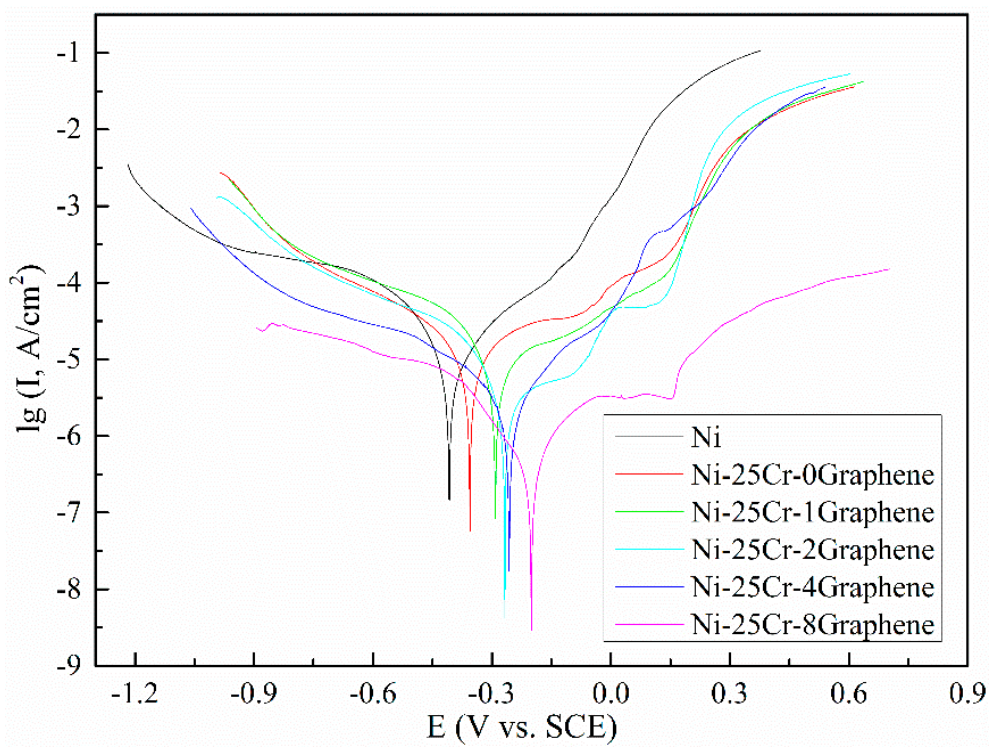

Figure 13. Potentiodynamic polarization curves of the $\mathrm{Ni}-\mathrm{Cr}$-graphene coatings in $3.5 \% \mathrm{NaCl}$ solution.

Table 2. Corrosion characteristics of the Ni-Cr-graphene coatings in $3.5 \% \mathrm{NaCl}$ solution.

\begin{tabular}{cccccc}
\hline Ni-Cr-Graphene & $\boldsymbol{E}_{\mathbf{c o r r}}(\mathbf{V})$ & $\boldsymbol{R}_{\mathbf{p}}\left(\mathbf{k} \boldsymbol{\Omega} \cdot \mathbf{c m}^{\mathbf{2}}\right)$ & $\boldsymbol{b}_{\mathbf{a}}\left(\mathbf{V} \cdot \mathbf{d e c}^{-\mathbf{1}}\right)$ & $\boldsymbol{b}_{\mathbf{c}}\left(\mathbf{V} \cdot \mathbf{d e c}^{\mathbf{- 1}}\right)$ & $\boldsymbol{i}_{\text {corr }}\left(\boldsymbol{\mu} \mathbf{A} / \mathbf{c m}^{\mathbf{2}}\right)$ \\
\hline Ni & -0.41 & 4.38 & 0.16 & -0.13 & 7.01 \\
Ni-25-Cr-0-Graphene & -0.36 & 5.39 & 0.16 & -0.15 & 6.22 \\
Ni-25-Cr-1-Graphene & -0.29 & 6.17 & 0.21 & -0.12 & 5.32 \\
Ni-25-Cr-2-Graphene & -0.27 & 15.29 & 0.33 & -0.13 & 2.67 \\
Ni-25-Cr-4-Graphene & -0.26 & 18.38 & 0.15 & -0.19 & 1.93 \\
Ni-25-Cr-8-Graphene & -0.20 & 85.50 & 0.12 & -0.14 & 0.33 \\
\hline
\end{tabular}

The EIS plots (Nyquist plots and Bode plots) of the Ni-Cr-graphene coatings are shown in Figure 14. In Figure 14a, the Nyquist curves of all the coatings exhibited a single semicircle, and the semicircle diameter of the $\mathrm{Ni}-\mathrm{Cr}$-graphene coating increased with increasing graphene concentration, always remaining larger than that of the pure Ni coating. In Figure 14b, both the Bode phase maximum and the Bode impedance modulus $\left(Z_{\mathrm{mod}}\right)$ of the Ni-Cr-graphene coating increased as graphene concentration increased. Moreover, the Bode phase evolution (Figure 14b) reflected a fixed constant for all coatings. The equivalent circuit (Figure 15) was used to fit Nyquist curves, in which $C P E_{\mathrm{dl}}, R_{\mathrm{ct}}$, and $R_{\mathrm{S}}$ represent the non-ideal double-layer capacitance, the charge transfer resistance, and the solution resistance, respectively. Table 3 exhibits the calculated values of each circuit element. The $R_{\mathrm{ct}}$ value of the Ni-Cr-graphene coating increased from 37.3 to $861.5 \mathrm{k} \Omega \cdot \mathrm{cm}^{2}$ as the graphene concentration increased from 0 to $8 \mathrm{~g} / \mathrm{L}$, always remaining larger than that of the pure Ni coating $\left(10.2 \mathrm{k} \Omega \cdot \mathrm{cm}^{2}\right)$. 

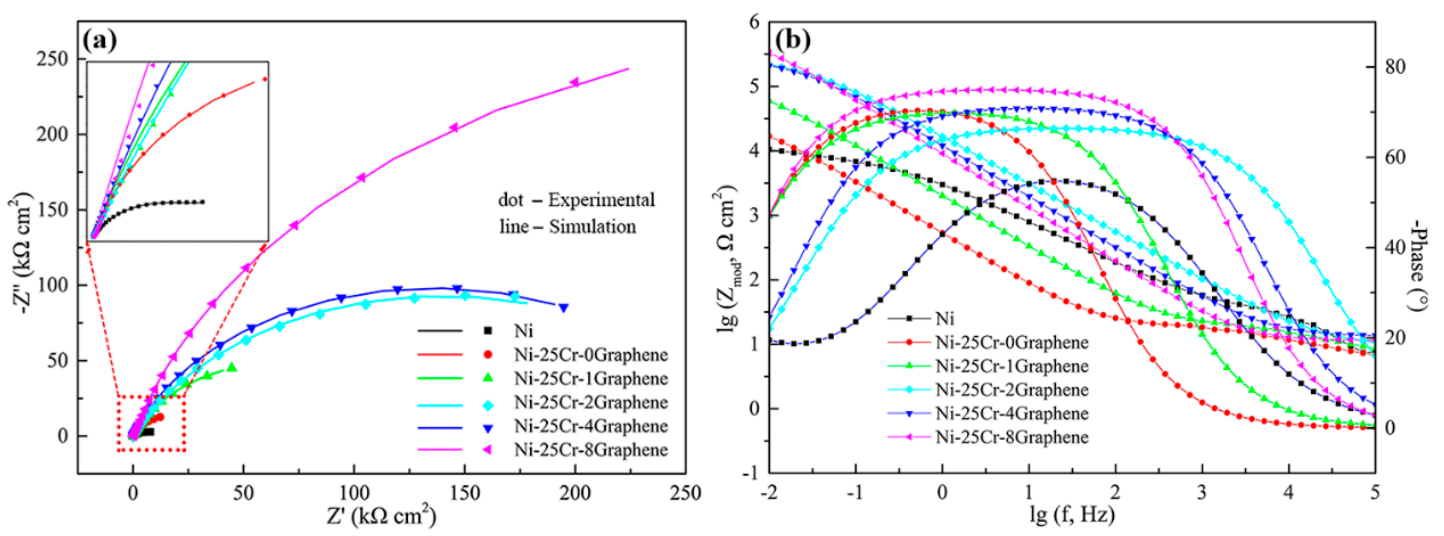

Figure 14. Nyquist plots (a) and Bode plots (b) of the Ni-Cr-graphene coatings in $3.5 \% \mathrm{NaCl}$ solution.

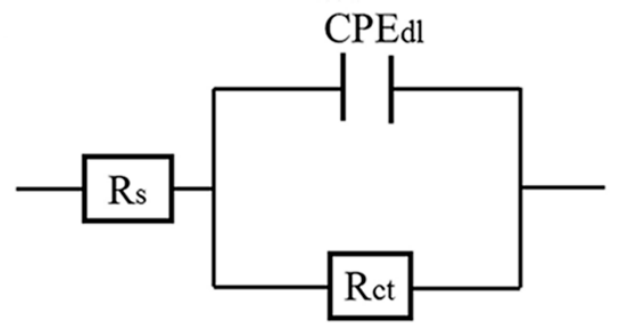

Figure 15. Equivalent circuit of the $\mathrm{Ni}-\mathrm{Cr}$-graphene coatings in $3.5 \% \mathrm{NaCl}$ solution.

Table 3. Corrosion factors from equivalent circuits of the Ni-Cr-graphene coatings.

\begin{tabular}{|c|c|c|c|c|}
\hline Ni-Cr-Graphene & $R_{\mathrm{ct}}\left(\mathrm{k} \Omega \cdot \mathrm{cm}^{2}\right)$ & $R_{\mathrm{s}}\left(\Omega \cdot \mathrm{cm}^{2}\right)$ & $C P E_{\mathrm{dl}}\left(\mu \mathrm{F} \cdot \mathrm{cm}^{-2}\right)$ & $n$ \\
\hline $\mathrm{Ni}$ & 10.2 & 7.5 & 85.5 & 0.65 \\
\hline Ni-25-Cr-0-Graphene & 37.3 & 6.8 & 426.8 & 0.61 \\
\hline Ni-25-Cr-1-Graphene & 137.6 & 8.7 & 115.7 & 0.79 \\
\hline $\mathrm{Ni}-25-\mathrm{Cr}-2-\mathrm{Graphene}$ & 272.1 & 7.1 & 189.2 & 0.79 \\
\hline Ni-25-Cr-4-Graphene & 280.4 & 9.1 & 37.9 & 0.75 \\
\hline Ni-25-Cr-8-Graphene & 681.5 & 8.4 & 233.5 & 0.84 \\
\hline
\end{tabular}

\section{Discussion}

In Figure 2, it can be seen that the regular pyramidal surface structure of the pure Ni coating changed to the dendrite like structure of the $\mathrm{Ni}-\mathrm{Cr}$-graphene coating as the graphene concentration increased in the electrolyte. The results suggested that the addition of graphene particles to the electrolyte strongly influenced the surface morphology evolution of the $\mathrm{Ni}-\mathrm{Cr}$-graphene coatings, which was believed to be induced by the electric conductivity of the graphene $[9,26]$.

Figure 3 shows that the $\mathrm{Cr}$ contents in the $\mathrm{Ni}-\mathrm{Cr}$-graphene coatings were almost consistent (ca. 7.7 wt.\%). This was caused by the certain Cr concentration of $25 \mathrm{~g} / \mathrm{L}$ in the electrolyte for all the coatings. The electrodeposition behaviors of $\mathrm{Cr}$ particles were sustainable and stable, and they were seldom disturbed by the co-deposition of graphene particles. In Figures 4 and 5, it can be observed that the graphene content in the $\mathrm{Ni}-\mathrm{Cr}-$ graphene coating increased with increasing graphene concentration. This was caused by the increased possibility of graphene particles adsorbing onto the cathode as the graphene concentration in the electrolyte increased [27]. The EDS (Figure 3) and Raman (Figure 5) results further illustrated that the $\mathrm{Ni}-\mathrm{Cr}$-graphene composite coatings were successfully established.

The XRD evolution in Figure 6 reflected the microstructure changes of Ni deposits in the $\mathrm{Ni}-\mathrm{Cr}$-graphene coatings with increasing graphene concentration. The calculated crystallite size of $\mathrm{Ni}$ deposits by Rietveld refinement is exhibited in Figure 8. Comparing the crystallite size evolution (Figure 8) with the results of EDS and Raman analysis (Figures 3-5), it was rational to consider that the addition of particles induced the decreased size of the Ni crystallites. In the electrodeposition process, 
the locations where the suspended particles were adsorbed could be deemed as the growth centers of Ni crystallites [2,28]. The adsorbed $\mathrm{Cr}$ particles prevented the further growth of $\mathrm{Ni}$ crystallites, simultaneously acting as the new nucleus to promote the crystallite refinement of $\mathrm{Ni}$ deposits in the $\mathrm{Ni}-\mathrm{Cr}$ coating $[2,28]$. With the further addition of graphene particles, the graphene particles could also work as the new nucleus, consequently leading to further crystallite refinement in the $\mathrm{Ni}-\mathrm{Cr}$-graphene coatings.

Figures 9-11 reflected the crystallite shape and crystallographic orientations of the Ni deposits in the Ni-Cr-graphene coatings. It was authenticated that the [100] orientation was the preferred orientation of the pure Ni coating in the Watts bath without particle additives, which could be changed by the co-deposition of particle additives in the electrolyte [2,4,29]. McCormack et al. [2] suggested that the co-deposition of $\mathrm{Y}_{2} \mathrm{O}_{3}$ particles led to the increase of [111] orientation of Ni-Y2O3 coatings. For the Ni-Cr-graphene coatings, the [100] growth orientation of the Ni crystallites could be disturbed by the co-deposition of $\mathrm{Cr}$ and graphene particles. The co-deposited particles precluded further growth of the $\mathrm{Ni}$ crystallites, consequently shielding the growth sites of $\mathrm{Ni}$ ions in the Watts bath $[2,28]$. Meanwhile, the nucleation of Ni crystallites took place on the particles, and the [111] orientation formed. Thus, the higher concentration of graphene particles led to a weaker [200] fiber texture in the $\mathrm{Ni}-\mathrm{Cr}$-graphene coatings.

As mentioned above, the co-deposition of the graphene particles gave birth to the decreased crystallite size and [200] texture of nickel deposits, which played important roles in the enhancement of the micro-hardness of the Ni-Cr-graphene coatings (see Figure 12a) based on the strengthening of crystallographic orientation and crystallite refinement. The crystallite refinement strengthening played an important role based on the Hall-Petch formula [30].

$$
\begin{gathered}
\sigma_{y}=\sigma_{0}+k d^{-1 / 2} \\
\text { Microhardness }=3 \sigma_{y}
\end{gathered}
$$

where $k, d, \sigma_{y}$, and $\sigma_{0}$ are the constant, the crystallite size, the yield stress, and the friction stress, respectively. The crystallographic orientation strengthening was based on the orientation relationship between the crystallographic orientation and the slip systems [31]. The $\{111\}<110>$ plane represented the slip system of Ni deposits. When the external stress was perpendicular to the (111) plane, the resolved shear stress in the slip system was zero, consequently resulting in the higher micro-hardness of (111) planes with respect to other planes. During the electrodeposition of the $\mathrm{Ni}-\mathrm{Cr}$-graphene coatings, more graphene particles brought about the further crystallite refinement and decreased [200] texture of Ni deposits. Therefore, the micro-hardness of the Ni-Cr-graphene coatings increased as the graphene concentration in the electrolyte increased. In Figure 12c, the less uniform distribution of the micro-hardness of the Ni-25-Cr-8-graphene coating could be understood by the surface irregularity of the coating. The co-deposition of graphene particles caused the surface irregularity of the coatings (see Figure 2), which led to the nonuniform distribution of micro-hardness [32].

In Figure 13 and Table 2, the $E_{\text {corr }}$ and $I_{\text {corr }}$ of the $\mathrm{Ni}-\mathrm{Cr}$-graphene coating increased and decreased with increasing graphene concentration, respectively. In Figure 14, showing the Nyquist and Bode plots, the corrosion resistance of the coatings could be determined by the magnitude of the semicircle diameter, Bode phase maximum, and $Z_{\text {mod }}[33,34]$. A larger semicircle diameter, Bode phase maximum, and $Z_{\text {mod }}$ indicated the better corrosion resistance of the Ni-Cr-graphene coatings. Therefore, the results of $I_{\text {corr }}$ and $R_{\text {ct }}$ indicated that the corrosion resistance of the $\mathrm{Ni}-\mathrm{Cr}$-graphene coating increased with increasing graphene concentration.

The incorporation of graphene particles and the microstructure changes of $\mathrm{Ni}$ deposits significantly enhanced the corrosion resistance of the Ni-Cr-graphene coatings. Firstly, the addition of graphene particles brought about further crystallite refinement and the a diminution of the [200] texture of $\mathrm{Ni}$ deposits in the $\mathrm{Ni}-\mathrm{Cr}$-graphene coatings compared to the $\mathrm{Ni}$ and $\mathrm{Ni}-\mathrm{Cr}$ coatings, reducing rapid corrosion paths and facilitating the formation of a passivation film [34,35]. Secondly, 
the graphene particles worked as "physical barriers" in the corrosion paths to hinder the spread of the corrosion [36]. Thus, the corrosion resistance of the Ni-Cr-graphene coating increased when the graphene concentration in the electrolyte increased.

\section{Conclusions}

As modification additives, different amounts of graphene particles, together with $25 \mathrm{~g} / \mathrm{L} \mathrm{Cr}$ particles, were used to fabricate $\mathrm{Ni}-\mathrm{Cr}$-graphene coatings in a Watts bath by electrodeposition. The co-deposition of graphene particles led to a dendrite-like structure of the $\mathrm{Ni}$-Cr-graphene coating instead of the regular pyramidal surface structure of the pure Ni coating. For all coatings, the amounts of $\mathrm{Cr}$ particles incorporated in the coatings were ca. $7.7 \mathrm{wt} . \%$, while the graphene content in the coatings increased when the graphene concentration in the electrolyte increased.

The increased graphene content in the coating brought about microstructure changes of the $\mathrm{Ni}$ deposits in the Ni-Cr-graphene coatings, such as crystallite size, crystallite shape, and crystallographic orientation. With increasing graphene concentration in the electrolyte, the crystallite size and [200] texture of the $\mathrm{Ni}$ deposits gradually decreased. The microstructure changes of the Ni deposits contributed to the enhancement in micro-hardness and corrosion resistance of the $\mathrm{Ni}$-Cr-graphene coatings. Therefore, the graphene particles successfully played the role of modification particles for the Ni-Cr coating by further optimizing the microstructure and properties of the coatings.

Author Contributions: Data curation, L.M.; formal analysis, L.M.; investigation, L.M.; writing-original draft preparation, L.M.; funding acquisition, C.H. and Q.H.; project administration, C.S., Q.H., and C.H.; supervision, C.S.; methodology, L.M.; writing-review and editing, Q.H. and C.S. All authors have read and agreed to the published version of the manuscript.

Funding: This research was funded by the Shanghai Commission of Science and Technology, grant number 18DZ1206300, the National Natural Science Foundation of China, grant number 51909156, and the China Postdoctoral Science Foundation, grant number 2016M591651.

Acknowledgments: The authors thank the Research Testing Center of Ocean Science and Engineering College for the SEM and XRD measurements.

Conflicts of Interest: The authors declare no conflicts of interest.

\section{References}

1. Peng, X.; Zhang, Y.; Zhao, J.; Wang, F. Electrochemical corrosion performance in $3.5 \% \mathrm{NaCl}$ of the electrodeposited nanocrystalline Ni films with and without dispersions of Cr nanoparticles. Electrochim. Acta. 2006, 51, 4922-4927. [CrossRef]

2. McCormack, A.G.; Pomeroy, M.J.; Cunnane, V.J. Microstructural development and surface characterization of electrodeposited nickel/yttria composite coatings. J. Electrochem. Soc. 2003, 150, C356-C361. [CrossRef]

3. Lecina, E.G.; Urrutia, I.G.; Díez, J.A.; Morgiel, J.; Indyka, P. A comparative study of the effect of mechanical and ultrasound agitation on the properties of electrodeposited $\mathrm{Ni} / \mathrm{Al}_{2} \mathrm{O}_{3}$ nanocomposite coatings. Surf. Coat. Technol. 2012, 206, 2998-3005. [CrossRef]

4. Qu, N.S.; Zhu, D.; Chan, K.C. Fabrication of Ni-CeO 2 nanocomposite by electrodeposition. Scripta Mater. 2006, 54, 1421-1425. [CrossRef]

5. Cai, F.; Jiang, C.; Wu, X. X-ray diffraction characterization of electrodeposited Ni-Al composite coatings prepared at different current densities. J. Alloys Compd. 2014, 604, 292-297. [CrossRef]

6. Zhao, G.; Zhou, Y.; Zhang, H. Sliding wear behaviors of electrodeposited Ni composite coatings containing micrometer and nanometer Cr particles. Trans. Nonferrous Met. Soc. China 2009, 19, 319-323. [CrossRef]

7. Dong, Z.; Peng, X.; Guan, Y.; Li, L.; Wang, F. Optimization of composition and structure of electrodeposited $\mathrm{Ni}-\mathrm{Cr}$ composites for increasing the oxidation resistance. Corros. Sci. 2012, 62, 147-152. [CrossRef]

8. Sun, J.; Du, D.X.; Lv, H.F.; Zhou, L.; Wang, Y.G.; Qi, C.G. Microstructure and corrosion resistance of pulse electrodeposited Ni-Cr coatings. Surf. Eng. 2015, 31, 406-411. [CrossRef]

9. Zhao, Y.; Jiang, C.; Xu, Z.; Cai, F.; Zhang, Z.; Fu, P. Microstructure and corrosion behavior of Ti nanoparticles reinforced Ni-Ti composite coatings by electrodeposition. Mater. Design 2015, 85, 39-46. [CrossRef] 
10. Yang, X.; Peng, X.; Wang, F. Hot corrosion of a novel electrodeposited Ni-6Cr-7Al nanocomposite under molten $(0.9 \mathrm{Na}, 0.1 \mathrm{~K})_{2} \mathrm{SO}_{4}$ at $900{ }^{\circ} \mathrm{C}$. Scripta Mater. 2007, 56, 891-894. [CrossRef]

11. Masoudi, M.; Hashim, M.; Kamari, H.M.; Salit, M.S. Fabrication and characterization of Ni-SiC-Cr nanocomposite coatings. Appl. Nanosci. 2013, 3, 357-362. [CrossRef]

12. Whitby, R.L.D. Chemical control of graphene architecture: Tailoring shape andproperties. ACS Nano 2014,8, 9733-9754. [CrossRef] [PubMed]

13. Algul, H.; Tokur, M.; Ozcan, S.; Uysal, M.; Cetinkaya, T.; Akbulut, H.; Alp, A. The effect of graphene content and sliding speed on the wear mechanism of nickel-graphene nanocomposites. Appl. Surf. Sci. 2015, 359, 340-348. [CrossRef]

14. Kumar, C.M.P.; Venkatesha, T.V.; Shabadi, R. Preparation and corrosion behavior of Ni and Ni-graphene composite coatings. Mater. Res. Bull. 2013, 48, 1477-1483. [CrossRef]

15. Jabbar, A.; Yasin, G.; Khan, W.Q.; Anwar, M.Y.; Korai, R.M.; Nizamb, M.N.; Muhyodin, G. Electrochemical deposition of nickel graphene composite coatings: Effect of deposition temperature on its surface morphology and corrosion resistance. RSC Adv. 2017, 7, 31100-31109. [CrossRef]

16. Chen, J.; Li, J.; Xiong, D.; He, Y.; Ji, Y.; Qin, Y. Preparation and tribological behavior of Ni-graphene composite coating under room temperature. Appl. Surf. Sci. 2016, 361, 49-56. [CrossRef]

17. Lutterotti, L. Maud Version 2.33, MAUD Materials Analysis Using Diffraction. Available online: http: //www.ing.unitn.it/ \{\}maud/Tutorial (accessed on 23 January 2011).

18. Young, R.A.; Wiles, D.B. Profile shape functions in Rietveld refinements. J. Appl. Crystallogr. 1982, 15, 430-438. [CrossRef]

19. Sindhu, M.; Ahlawat, N.; Sanghi, S.; Agarwal, A.; Dahiya, R.; Ahlawat, N. Rietveld refinement and impedance spectroscopy of calcium titanate. Curr. Appl. Phys. 2012, 12, 1429-1435. [CrossRef]

20. Popa, N.C. The (hkl) dependence of diffraction-line broadening caused by strain and size for all Laue groups in Rietveld refinement. J. Appl. Crystallogr. 1998, 31, 176-180. [CrossRef]

21. Warren, B.E. X-ray Diffraction; Addison-Wesley: Reading, MA, USA, 1969; pp. 251-305.

22. Harimkar, S.P.; Dahotre, N.B. Crystallographic and morphological textures in laser surface modified alumina ceramic. J. Appl. Phys. 2006, 100, 024901-024906. [CrossRef]

23. Zhao, Y.; Cai, F.; Wang, C.; Chai, Z.; Zhu, K.; Xu, Z.; Jiang, C. Investigation on the evolution of microstructure and texture of electroplated Ni-Ti composite coating by Rietveld method. Appl. Surf. Sci. 2015, 353, 1023-1030. [CrossRef]

24. Murugesan, S.; Kuppusami, P.; Mohandas, E.; Vijayalakshmi, M. X-ray diffraction Rietveld analysis of cold worked austenitic stainless steel. Mater. Lett. 2012, 67, 173-176. [CrossRef]

25. Bozzini, B. Mass-transport effects on texture formation of nickel electrodeposits. Mater. Chem. Phys. 2000, 66, 278-285. [CrossRef]

26. Hasannaeimi, V.; Shahrabi, T.; Sanjabi, S. Fabrication of NiTi layer via co-electrodeposition of nickel and titanium. Surf. Coat. Technol. 2012, 210, 10-14. [CrossRef]

27. Cai, F.; Jiang, C. Influences of Al particles on the microstructure and property of electrodeposited Ni-Al composite coatings. Appl. Surf. Sci. 2014, 292, 620-625. [CrossRef]

28. Garcia, I.; Conde, A.; Langelaan, G.; Fransaer, J.; Celis, J.P. Improved corrosion resistance through microstructural modifications induced by codepositing SiC-particles with electrolytic nickel. Corros. Sci. 2003, 45, 1173-1189. [CrossRef]

29. Amblard, J.; Epelboin, I.; Froment, M.; Maurin, G. Inhibition and nickel electrocrystallization. J. Appl. Electrochem. 1979, 9, 233-242. [CrossRef]

30. Furukawa, M.; Horita, Z.; Nemoto, M.; Veliev, R.Z.; Langdon, T.G. Microhardness measurements and the Hall-Petch relationship in an Al-Mg alloy with submicrometer grain size. Acta Mater. 1996, 44, 4619-4629. [CrossRef]

31. Chen, C.T.; Song, Y.C.; Yu, G.P.; Huang, J.H. Microstructure and hardness of hollow cathode discharge ion-plated titanium nitride film. J. Mater. Eng. Perform. 1998, 7, 324-328. [CrossRef]

32. Zhao, Y.; Wang, L.; Sun, Y.; Liu, H.; Jiang, C.; Ji, V.; Li, W. Influences of Al and Ti particles on microstructure, internal stress and property of Ni composite coatings. J. Alloys Compd. 2019, 793, 314-325. [CrossRef]

33. Yuan, S.; Pehkonen, S. Surface characterization and corrosion behavior of 70/30 Cu-Ni alloy in pristine and sulfide-containing simulated seawater. Corros. Sci. 2007, 49, 1276-1304. [CrossRef] 
34. Zhao, Y.; Wang, L.; Qin, Z.; Wang, C.; Xu, Z.; Jiang, C.; Ji, V. The roles of Ti particles in improving the corrosion resistance of electrochemically assembled Ni-Ti composite coatings. J. Sci. Eng. 2017, 73, 1107-1118. [CrossRef]

35. Cai, F.; Jiang, C.; Zhang, Z.; Muttini, E.; Fu, P.; Zhao, Y.; Ji, V. Fabrication and characterization of Ni-Zr composite coatings using electrodepositing technique. J. Alloys Compd. 2015, 635, 73-81. [CrossRef]

36. Baghery, P.; Farzam, M.; Mousavi, A.B.; Hosseini, M. Ni-TiO 2 nanocomposite coating with high resistance to corrosion and wear. Surf. Coating. Technol. 2010, 204, 3804-3810. [CrossRef]

(C) 2020 by the authors. Licensee MDPI, Basel, Switzerland. This article is an open access article distributed under the terms and conditions of the Creative Commons Attribution (CC BY) license (http://creativecommons.org/licenses/by/4.0/). 